\title{
WHY IS AN ETHICAL AND INTEGRATED AUdiT ACCREDITATION PROCESS REQUIRED FOR ROMANIAN HOSPITALS?
}

\author{
Daniela-Tatiana Agheorghiesei (Corodeanu), Liliana Iliescu, \\ Cristina Gavrilovici and Liviu Oprea \\ Center for Health Policy and Ethics, "Grigore. T. Popa" \\ University of Medicine and Pharmacy, Iași, România
}

Accepted: December 2013

\begin{abstract}
Nowadays, a third generation of ethics has come to the fore, whereby ethical issues are approached in an integrated manner, emphasising the management of ethics, which entails a cause-effect relation. One of its evaluation instruments is the ethical audit.

This paper presents the findings of research focused on 47 executives involved in the management of quality in Romanian hospitals. The research concerns, in particular, the relevance and the opportunity for an ethical audit and the assessment of its possible effects.

The data were gathered using a questionnaire.

The research shows that Romanian managers consider the introduction of the ethical audit within the accreditation process as being relevant and pertinent. They believe that ethical monitoring is beneficial for the activity of healthcare institutions, but also that these institutions are as yet not sufficiently prepared to implement ethical audits. This study might be useful for sounding an alarm bell or for suggesting a direction for the qualitative and quantitative improvement of accreditation criteria and for the management of change in healthcare institutions worldwide.
\end{abstract}

Key words: ethics in healthcare management, Romanian healthcare managers, ethical audit, accreditation

JEL: I18, MOO, M42

\section{1 \\ Introduction}

Institutions in the healthcare system now have responsibilities beyond just patient rights or even the rights of employees. Their management as with any other organisation, is faced with the need to manage limited resources and competition. Moreover, healthcare institutions are subject to strong public scrutiny and must gain the trust and approval of accreditation bodies.

This article assumes that the world at large has entered the third generation of ethics and has made the transition to a higher level of ethical issues and methods of solving them. Our study presents the results of empirical research which aims to identify the opinions of executives involved in quality assurance in hospitals regarding the relevance of and opportunity for the introduction of the ethical audit within the accreditation system for hospitals in Romania.

It will add to the small body of studies in the field. We believe that our study could be useful for all countries wishing to strengthen public confidence in the health system by including ethical audits in accreditation criteria. Our research primarily conveys the message that managers involved in quality assurance in hospitals should be consulted, because they are the experts needed to support this process and provide information necessary for its implementation. Furthermore, the research highlights issues and questions that may be considered in consultation with managers. 
2

\section{Literature review}

\subsection{The multiple facets of ethics in the management of the healthcare system and its institutions}

The principles, methods, strategies, instruments of ethics and good practices used in the management of hospitals and other healthcare units is a wide field of study, intensely analysed and debated in the scholarly literature from multiple points of view. Several issues have been analysed since the late 1990s: civic responsibility of the healthcare organisation (Hofmann, 1995); the evaluation of the ethical program (Neft-Smith, Scott, Edward \& Fletcher, 1997); good practices in the ethics of hospital units (Cassidy, 1998); ethical leadership (Johnston, Cruess \& Cruess, 2001; Dolan, 2004; ) and the challenges raised by ethics and the responsibilities of leaders in the healthcare system (Squazzo, 2012); ethical dimensions in public healthcare policies (Roberts \& Reich, 2002); ethics and the safety of hospitals (Weinstein, 2002) and ethics and patient safety (Lachman, 2008); challenges of ethical committees (Collier \& Sandborg, 2006; Hogstel \& Curry, 2004); the ethics of decision-making (Maddalena, 2007; Slosar, 2004); ethical transparency and economic medicalisation (Poitras \& Meredith, 2009); the organisational costs of ethical conflicts (Nelson, Weeks \& Campfield, 2008; Hofmann, 2012); and the ethics of decisions concerning the allocation of resources (Hofmann, 2011). The aforementioned issues have the commonality that if they are not considered properly, they can weaken quality of care and organisational performance. The numerous published studies show the complexity of the subject and the many ethical risks which might beset the proper functioning of the healthcare system. They also highlight the need for preparation and prevention, a willingness to approach them attentively, to analyse them according to their particularities, and to frame them optimally in the managerial process by finding adequate instruments for dealing with them. These articles also implicitly envisage the role, importance and structure of the ethical audit (Morrell, 2002; Kirkpatrick, Reamer \& Sykulski, 2006). As Porter (1994:38) high- lights, audit practices (and here we can include the ethical audit) have spread "due to changes in public sector management and new prominent ideals of quality, governance and accountability."

Another aspect which deserves full consideration is the inclusion of ethics within the accreditation system of healthcare units, highlighting thus the impact of ethics on stakeholders and on the quality of services provided. This would mean moving ethics from the abstract into reality, and rather than taking a declarative stance moving it to the implementation level. The fact that the accreditation process verifies whether the institution has a system for handling patient complaints does not fully demonstrate the functionality of the system. Only proper consultation of employees and patients regarding the ethical connotations of processes would show the ethical performance of an institution which differentiates it from other institutions.

Hoffman (1995) and Wu, Liao, Chiu, Lin and Yang (2011) debate the relevance of and the opportunity for the ethical audit within the accreditation process of hospitals). This article focuses on the latter aspect.

\subsection{The third generation of ethics: the management of ethics and auditing}

Towards the end of 1990s, Dr. Bart Colopy (in Cassidy, 1998) maintained that the ethical discourse had already entered the second generation of ethics. The first generation focused on the rights of patients, the quality of healthcare services and its effects, and on ethical issues related to decision-making involved in the choice of treatment regarding the assurance of life. For the author mentioned above, the second generation highlighted aspects of organisational and non-clinical ethics (ways of dealing with employees, allocation of budget, handling of conflicts of interests, prioritisation of certain healthcare services at the highest qualitative level for the patient, even in situations where this level is difficult to attain, etc.).

Apart from the economic pressures specific for a transition period, there are serious ethical dilemmas, rendered more urgent by the fact that one of the ethical responsibilities of organisations which provide healthcare services 
is taking the role of leadership in the improvement of healthcare in communities, in spite of financial difficulties and of the paradoxical situation that the problem of attracting resources from healthcare insurance is resolved by the high degree of employment in hospitals (Hofmann, 1995). Contemporary challenges for the worldwide management of the healthcare system are generated by diverse factors: technological; economic; socio-political; and cultural. According to the Joint Commission on Accreditation of Healthcare Organizations ${ }^{1}$ (1998:1), the necessity of dealing with moral issues was determined in the last 30 years by scientific progress in reproductive technology and by concern for the fragile medical state of new-borns and by the effects of technological development upon prolonging life expectancy. In addition morality was also determined by a wider awareness regarding the legal and moral rights of patients, including the right to selfdetermination, by a progressive change in vision regarding the financing of the healthcare system from "fee to service" to "managed care", by an enhancement of cultural, ethnic and spiritual diversity, by the rapid aging of populations which influenced the role of caretakers within the core family, and by a new philosophy concerning the meaning of "endof-life care". These factors take different forms today, some of which are worrying for political decision-makers and leaders: the lack of resources; limited access to medical assistance for uninsured categories of the population; the migration of doctors and of medical personnel; the internationalisation of access to healthcare; and political changes in general. Consequently, all these factors demand new visions and strategies, societal changes which bring about institutional modifications, and an approach at a superior level to ethical issues in the healthcare field. Apart from these high-level issues, there are also ethical dilemmas at an individual level which confront medical personnel, such as the case of doctors who must balance the obligation towards patients with their professional oath and with the obligation towards employers (Loewy, 1999), all with their own particular challenges.

These aspects, analysed in scholarly literature, are today presented in an integrated form, in a type of cause-effect relationship. If the first generation of ethics took into account patients' rights regarding access to healthcare services, today we have to deal with the problem of quality of this service and implicitly with the question of patients' perception of its quality. Therefore, the new orientation takes into account patients' opinions, either for the prevention, or for the improvement, through remedies, of medical services. There is, thus, the challenge of the evaluation of an ethical culture and values (orientation towards quality, excellence, listening and involving the patient, transparency, responsibility) which are predominant in an organisation, with reference to the satisfaction of patients. The latter is known as the third generation of ethics.

The third generation of ethics is responsible for the proper management of ethical behaviour, and applies to the managers who hold responsibility for observing ethical standards (Weber, 2001:13). The management of ethical conduct means the identification of risk areas so that the organisation is able to maintain a high degree of trust from the public, and so that it passes the test of accomplishing the accreditation standards required by external evaluators and can thus take an honourable place within the classification processes of hospitals. Apart from the aspects embodied by the previous generations, there is the additional need for a strong focus on the identification, through auditing, of the impact of initiatives deemed to establish an ethical climate and to prevent ethical risks within and outside the organisation (ethical culture and the satisfaction of patients, leadership, ethical climate and the satisfaction of employees). There is also the need for the voluntary use of managerial instruments which ensure both ethical behaviour within organisations and in their external relations, and the learning process (ethical policies, ethical programs, officer/ethical counsellor, ethical help lines, medical ethical committees, ethical codes, ethical quality management and ethical training). These instruments ensure integration and recognition within specific networks (ethical associations, partnerships with educational institutions), as well as the assessment of efforts and of the impact of these ethical measures (programmes that monitor the ethical climate, ethical audits). New requirements from the community, such 
as the fair handling of diversity, care for the environment, the involvement of the organisation in projects with a social responsibility, represent new challenges for organisations whose mission consists of providing healthcare. In order to deal with all these factors and requirements, the organisation needs an integrated system of ethical management which includes ethical vision, ethical competencies, instruments of planning, organising, leadership, decision-making and evaluation, access to networks, availability and capacity to learn and ethical training. The third generation of ethics also envisages the evaluation of integrity and the ethical reputation of an organisation (through the assessment of the degree of trust) and conformity with the institutional systems of accreditation (see figure 1).

Figure 1

The three generations of ethics in healthcare organisations

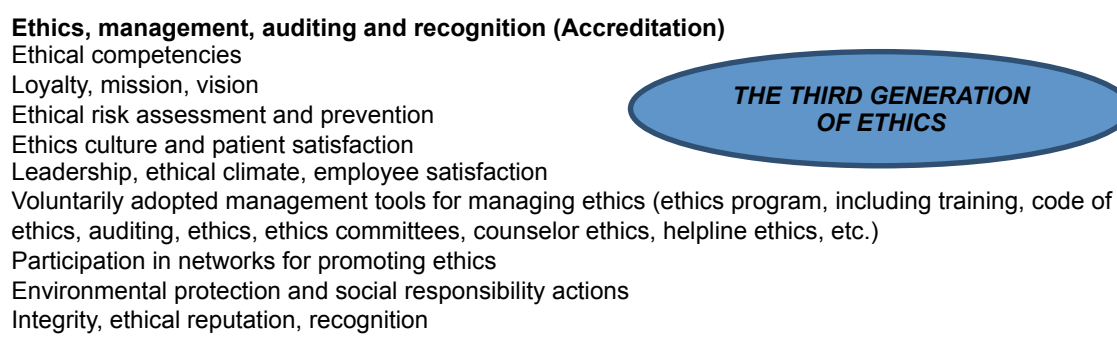

Ethics and organisational issues (non-clinical) Organisational ethics

Ethical treatment of employees (rights)

Resolving ethical conflicts

Budget allocation

Promoting medical care at the highest level of quality in the context of restraints

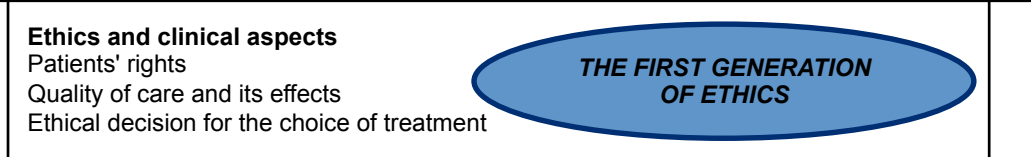

Source: authors, adapted from the presentation of the first two generations of ethics mentioned by Dr. Bart Colopy in Cassidy (1998)

Understanding this transition from the first generation of ethics to the third generation is extremely important for the acceptance of the role of the ethical audit in the ethics and quality management of hospitals, and of the introduction of this audit as an accreditation criterion. In other words, managers and responsible authorities could better realise the need to address ethical issues at a broader level, according to the current context in which their institutions operate. Pressures to reduce costs and focus on other priorities, lack of ethical skills (conducting an ethical audit would require "formal education or training related to professional ethics" (Reamer, 2007: 186)), but also lack of vision and indifference can block managers, causing them to stay at the stage of second generation ethics. This in turn may affect long-term organisational performance, especially in terms of public confidence.

\subsubsection{The tools needed for managing ethical issues and risks: the relevance of the ethical audit}

One of the instruments, which makes possible timely identification and dealing with ethical risks areas, with multiple advantages, is the ethical audit. According to Kaptein (1998:60), the ethical audit is a process which describes, analyses and evaluates the relevant aspects of the ethics in an organisation.

Hofmann (1995) defines the ethical audit from the perspective of guaranteeing to stakeholders the implementation of the mission originally assumed by the organisation, "even 
in the most difficult times". Also the ethical audit is "... a practical and valuable instrument in evaluating whether the organization complies with its standards and expectations" (Hofmann, 2006), which in unfavourable contexts, implies taking risks and facing a large range of potentially negative consequences. Wiley (1995, as cited by Menzel (2007:72)) considers that the ethical audit has the role of improving the organisation's performance. In the wake of evaluations, the audit offers management certain focal topics such as: the climate; the working environment; and the codes and consolidation of ethical policies of the organisation.

The ethical audit is based on a process of analysis and is a true mechanism of dialogue and of gathering suggestions for improvement. It generates trust regarding external stakeholders, guaranteeing to them that the organisation fulfils its economic, social and environmental obligations (García-Marzá, 2005). The ethical audit makes it possible to apply ethical issues to professional practices, to survey and evaluate, where necessary, the adequacy of these practices, and to monitor the application the quality assurance strategy (Reamer, 2007). It also represents a barometer of organisational well-being by compiling a list which verifies the degree of conformity to ethical standards, written or unwritten (Schlegelmilch, 1998:128). It evaluates the fidelity of the organisation towards the values, mission and the ethical code as declared and assumed initially by the organisation. It also assesses aspects regarding the way in which the organisation respects its internal and external stakeholders and their moral and legal rights (employees, patients, clients, providers, volunteers, community). The audit is also part of the construction and the maintenance of ethical climate, it makes place for ethics in communication and leadership and develops practices for financial management, marketing and funding.

Ferrell, Ferrell and Fraedrich (2012:244245) and Menzel (2007:72) focus on a long list of benefits of the ethical audit. It has a preventive and proactive character because it makes it possible to track actions and behaviours which are mistaken, which produce ethical risks and crises within the organisation in real time. In this way, the audit minimises the potential costs of ethical conflicts and of unethical conduct. This type of audit motivates and assures the perception of an ethical climate and promotes satisfaction among employees. It protects the image and the good reputation of the organisation by avoiding uncontrolled situations and ethical risks which might compromise it. The internal audit cements good practices within organisations, boosting trust and good public opinion as well as credibility with financial institutions.

In this context the relevance and structure of the ethical audit used both in the management of the quality of hospitals and in the accreditation process are discussed next.

\section{3}

Methods

\subsection{Research aim}

Our research aim is to identify the opinion of hospital executives (involved in quality assurance) regarding the relevance of and the opportunity for the introduction of the ethical audit in the accreditation process of Romanian hospitals.

This research primarily took as its starting point the work of $\mathrm{Wu}$ et al. (2011) who studied the problem of including the ethical audit within the accreditation process of hospitals and their optimal structure, using a valid sample of 90 hospital managers in Taiwan. Also the work of Landman, Mouton and Nevhutalu (2001) from the Ethics Institute of South Africa, which shows the results of the ethical audit (conducted based on a questionnaire) at the Chris Hani Baragwanath Hospital was a cornerstone in supporting our approach. In Romania we have no similar studies related to consulting hospital managers involved in quality assurance on the integration of ethical audits into institutions' accreditation criteria.

\subsection{Research method and tools}

Our method for gathering the data was an inquiry based on a questionnaire including two parts and with a total of 59 items (including biographical data of respondents).

The questionnaire was chosen as the method of data collection because hospital managers involved in quality assurance who participated in the research are from hospitals across the 
country. Under these conditions, the research would have involved high costs and time constraints if not for the questionnaire. As Pienaar (2010:182) highlights, "In organisational research, ... business ethics, ... transgressions of organisational standards are sensitive". Also, as stated by an expert in research methodology (Chelcea, 2001:255), "the questionnaire is indispensable for knowledge of the phenomena of consciousness, constructed and mediated by language (knowledge, opinions, beliefs)."

\subsubsection{The design of the questionnaire and its distribution}

In the first part of the questionnaire (whose analysis and results are the subject of this article, see table 5 below), 20 questions related to the expressed opinions regarding the relevance of and the opportunity for introducing the ethical audit within the accreditation process of Romanian hospitals were formulated.

The second part of the questionnaire was comprised of questions related to aspects which would be adequate for the structure of an ethical audit, and which might be monitored in the course of the accreditation process of Romanian hospitals. Within the present paper we limit our research to the analysis of the answers obtained in the first part of the questionnaire. The second part of the questionnaire was the subject of another analysis, the results of which have already been published.

The questionnaire was examined by eight specialists who have an academic interest in healthcare ethics.

The questions were formulated so as to present multiple choices and an ordinal scale of response of the "Likert type" (1 - complete disaccord, 6 - complete accord). One of the questions was open-ended.

The questionnaire was formatted and distributed with the help of the "googledocs" application.

\subsubsection{Research subjects, sample method and characteristics of the sample}

In order to achieve the research objective, we applied a non-randomised sampling method called logical sampling. The questionnaire was applied online between January and July 2012 to 150 executives, all members of the target group within the framework of a European project on the topic of the management of quality in healthcare in Romanian institutions. They were informed during project meetings of the purpose of the questionnaire, and about the importance of the ethical audit for the quality assurance process.

The main reason for the selection of this target group was that its members are involved in hospital quality assurance, and as suggested by Porter (1994:1), the audit is part of the process "audit and other quality assurance initiatives". In addition "many audits, such as medicine, are conceived primarily as internal reviews to improve decision-making...intended to support rather than to discipline" (Porter, 1994:4). Ethical audit is a tool for monitoring the application of the quality assurance strategy (Reamer, 2007). Managers involved in quality assurance are those that provide the foundation for the quality of decisions by improving procedures and preventive controls. They know in detail all the strengths and weaknesses of the organisation's activities (are "the key informants"), and are the ones that provide all the necessary documentation for institutional accreditation given existing data. They are the closest to the "ethical audit", because they are the ones who know all the details of all organisational work processes.

The valid sample is represented by 47 subjects, which constitutes a response rate of 29 per cent from the analysed population.

The distribution of respondents according their gender, level of studies, type of education and age is presented below (in tables 1, 2, 3 and 4).

Table 1

Distribution of respondents according to gender

\begin{tabular}{|l|c|c|}
\hline Gender & Female & Male \\
\hline$\%($ No.) & $68 \%(N=32)$ & $32 \%(N=15)$ \\
\hline Total respondents & \multicolumn{2}{|c|}{$100 \%(\mathrm{~N}=47)$} \\
\hline
\end{tabular}


Table 2

Distribution of respondents according to their level of education

\begin{tabular}{|l|c|c|c|c|}
\hline Level of studies & Bachelor's degree & Master's degree & Doctoral & Post-doctoral \\
\hline$\%($ No.) & $66 \%(\mathrm{~N}=31)$ & $21.3 \%(\mathrm{~N}=10)$ & $8.5 \%(\mathrm{~N}=4)$ & $4.3 \%(\mathrm{~N}=2)$ \\
\hline Total respondents & \multicolumn{3}{|c|}{$100 \%(\mathrm{~N}=47)$} \\
\hline Ethical training & \multicolumn{3}{|c|}{$10.64 \%(\mathrm{~N}=5)$} \\
\hline
\end{tabular}

Table 3

Distribution of respondents according to field of study

\begin{tabular}{|l|c|c|c|c|}
\hline $\begin{array}{l}\text { Type of education } \\
\text { (studies) }\end{array}$ & Medical & Economic & Humanities & Technical \\
\hline$\%($ No.) & $40.4 \%(\mathrm{~N}=19)$ & $38.3 \%(\mathrm{~N}=18)$ & $12.8 \%(\mathrm{~N}=6)$ & $8.5 \%(\mathrm{~N}=4)$ \\
\hline Total respondents & \multicolumn{4}{|c|}{$100 \%(\mathrm{~N}=47)$} \\
\hline
\end{tabular}

Table 4

Distribution of respondents according to their age

\begin{tabular}{|l|c|c|c|c|}
\hline Age & $25-35$ years & $36-45$ years & $46-55$ years & over 55 years \\
\hline$\%($ No.) & $23.4 \%(\mathrm{~N}=11)$ & $40.4 \%(\mathrm{~N}=19)$ & $27.7 \%(\mathrm{~N}=13)$ & $8.5 \%(\mathrm{~N}=4)$ \\
\hline Total respondents & \multicolumn{3}{|c|}{$100 \%(\mathrm{~N}=47)$} \\
\hline
\end{tabular}

A percentage of 89.4 of the executives work for institutions which are publicly-funded, while the rest come from institutions funded from mixed resources. Of these institutions, 25.5 per cent are emergency hospitals, 17 per cent have a general profile, and 17 per cent provide medical services for patients who are chronically ill. In an equal percentage, 8.5 per cent are respondents from county hospitals and municipal hospitals respectively, 6.4 per cent are from academic hospitals, and 4,3 per cent from clinical units. A percentage of 40.4 are from institutions that have under 200 beds, 34 per cent have between 200 and 500 beds, and 25.5 per cent have over 500 beds.

\subsubsection{Data analysis}

The gathered data were analysed with the aid of the statistical program SfinxPlus ${ }^{2}$, under the licence of use for Alexandru Ioan Cuza University, Iaşi, Romania. The following methods and tests of analysis were put to work: analysis of frequencies; calculation of means and of standard deviations; and correlation tests.

\subsection{Research hypothesis}

Based on the literature we formulated the following hypotheses: 1) executives from
Romanian hospitals consider that the introduction of an ethical auditing would be relevant and welcome within the accreditation process of hospitals (Hofmann, 1995; Wu et al., 2011; Morrison, 2011); 2) they consider that the implementation of an ethical audit within the accreditation process would have a beneficial role regarding the activity of Romanian hospitals (Hofmann, 1995; Wu et al., 2011; Morrison, 2011); 3) they think that managers and healthcare institutions from Romania are not sufficiently prepared for the implementation of an ethical audit (Reamer, 2007); and 4) in their opinion, there is a strong correlation between the role of ethical auditing and the consolidation of the public's trust in the capacity of hospitals to provide medical service of superior quality (Domingo GarcíaMarzá, 2005; Menzel, 2007).

\section{4 \\ Results}

The averages of the answers for the 20 variables (related to each of the questions) which we will analyse further (from a total of 58 for the entire questionnaire) vary between 5.70 and 3.43 , with the total average being 4.79 (Table 5). 


\section{Table 5}

Research results showing respondents' opinions regarding the appropriateness of introducing ethical auditing in the accreditation process for Romanian hospitals

\begin{tabular}{|c|c|c|c|c|}
\hline Surveyed opinions & $\begin{array}{c}\text { Mean } \\
(\mathrm{M})\end{array}$ & $\begin{array}{c}\text { Standard } \\
\text { deviation } \\
(\sigma)\end{array}$ & Sum & Part \\
\hline $\begin{array}{l}\text { Ethical principles should represent an essential aspect of the management of each } \\
\text { hospital. }\end{array}$ & 5.70 & 0.66 & 268 & 2.3 \\
\hline Quality assurance is an issue related to ethical principles. & 5.55 & 0.75 & 261 & 2.2 \\
\hline $\begin{array}{l}\text { Hospital managers need additional training for policy formulation and } \\
\text { implementation of ethical standards. }\end{array}$ & 5.51 & 0.75 & 259 & 2.2 \\
\hline $\begin{array}{l}\text { The hospital accreditation process should include assessment of whether hospitals } \\
\text { meet ethical standards/adopt ethical behaviour. }\end{array}$ & 5.40 & 1.08 & 254 & 2.1 \\
\hline $\begin{array}{l}\text { Monitoring and auditing ethics would be beneficial for the management of } \\
\text { Romanian hospitals. }\end{array}$ & 5.38 & 0.97 & 253 & 2.1 \\
\hline $\begin{array}{l}\text { Introducing ethical auditing could help strengthen the community's confidence in the } \\
\text { ability of hospitals to provide high quality medical services. }\end{array}$ & 5.36 & 1.11 & 252 & 2.1 \\
\hline Ethical audit should evaluate ethics management. & 5.34 & 1.03 & 251 & 2.1 \\
\hline Introducing ethical auditing could help increase hospital performance. & 5.28 & 1.08 & 248 & 2.1 \\
\hline $\begin{array}{l}\text { The hospital accreditation process should include an audit/diagnostic on ethical } \\
\text { standards. }\end{array}$ & 5.26 & 1.09 & 247 & 2.1 \\
\hline $\begin{array}{l}\text { Hospital managers should be consulted regarding the introduction of an ethical } \\
\text { audit of their institution within the accreditation process. }\end{array}$ & 5.19 & 1.31 & 244 & 2.1 \\
\hline $\begin{array}{l}\text { Availability (of respondent) for involvement in carrying out an audit of ethics in the } \\
\text { hospital accreditation process. }\end{array}$ & 5.09 & 1.21 & 239 & 2.0 \\
\hline $\begin{array}{l}\text { Introducing an ethical auditing accreditation process could contribute to the } \\
\text { classification of hospitals. }\end{array}$ & 4.89 & 1.09 & 230 & 1.9 \\
\hline $\begin{array}{l}\text { The introduction of ethical auditing could be a criterion for allocating resources } \\
\text { more efficiently. }\end{array}$ & 4.79 & 1.32 & 225 & 1.9 \\
\hline $\begin{array}{l}\text { In every day activity there is a strong concern for promoting ethical values in } \\
\text { institutions. }\end{array}$ & 4.66 & 1.18 & 219 & 1.8 \\
\hline The institution could cope with a rigorous ethical audit process. & 4.30 & 1.40 & 202 & 1.7 \\
\hline $\begin{array}{l}\text { Respondents' familiarity with/possession of skills in terms of values, principles, } \\
\text { standards, ethical tools needed in the management of hospitals. }\end{array}$ & 3.85 & 1.60 & 181 & 1.5 \\
\hline $\begin{array}{l}\text { Hospital managers are sufficiently prepared for policy formulation and } \\
\text { implementation of ethical standards. }\end{array}$ & 3.66 & 1.43 & 172 & 1.4 \\
\hline $\begin{array}{l}\text { Hospital managers are sufficiently competent to formulate and implement policies } \\
\text { and ethical standards. }\end{array}$ & 3.64 & 1.42 & 171 & 1.4 \\
\hline $\begin{array}{l}\text { Romanian public hospitals are prepared for/ could handle an audit of ethical } \\
\text { standards. }\end{array}$ & 3.51 & 1.38 & 165 & 1.4 \\
\hline $\begin{array}{l}\text { Hospital managers receive sufficient support and resources for policy formulation } \\
\text { and implementation of ethical standards. }\end{array}$ & 3.43 & 1.26 & 161 & 1.4 \\
\hline Total & 4.79 & & 4502 & 100,0 \\
\hline
\end{tabular}

Analysis of the answers given emphasises that the most important and essential aspects for the management of healthcare institutions are: concern for quality $(\mathrm{N}=42 ; 89.4$ per cent $)$; efficiency $(\mathrm{N}=20 ; 42.6$ per cent); and good relations between patients and institutions $(\mathrm{N}=$ 18; 38.3 per cent). A percentage of $78.7(\mathrm{~N}=$ 37 ) of the questioned executives completely agree that respect for ethical principles represents an essential aspect of the management of healthcare institutions $(\mathrm{M}=5.70$; $\sigma=0.66)$. A percentage of 66 per cent of respondents $(\mathrm{N}=31)$ agreed completely that quality assurance must be related to ethics $(M=5.55 ; \sigma=0.75)$. These answers concur with the best-known ethical theories (Morrison, 2011:230). For example, the Kantian vision is that concern for quality constitutes a moral duty, even a categorical imperative and that all human beings are worthwhile and deserve quality services. In turn, the supporters of utilitarianism would consider lack of quality in services as an adverse consequence for individuals, as well as for the organisation, 
which translates into low satisfaction or outright dissatisfaction, or low wages and has adverse legal implications. Finally, Rawls' theory of justice argues for the importance of the interest of the community and of the organisation. The relationship between the two variables (that ethical principles represent an essential aspect of quality assurance management) is highly significant and has a positive correlation coefficient of 0.83 (Ecarttype of regression coefficient $=0.094$ ). In this case, the former explains 69 per cent of variance in the latter. These results are possibly justified by the fact that respondents are people involved in quality management of the institutions where they work.

A percentage of $57.4(\mathrm{~N}=27)$ of participants are in complete agreement that the accreditation process of hospitals should include the management of ethical values and organisational ethics, that is policies should be formulated and instruments introduced that support ethical standards $(\mathrm{M}=5.34$; $\sigma=1.03$ ). The correlation coefficient between the management of ethical values and organisational ethics within the accreditation process and the inclusion of the ethical values within the accreditation process is +0.88 . The first variable accounts for 76 per cent of variance in the second variable (Ecart-type of the regression coefficient - 0.076). Nevertheless, only 12 respondents (25.5 per cent) expressed complete agreement and 19 agreement (40.4 per cent), that in their institution there is on-going concern for the implementation of ethical values.

Over half of the respondents $(\mathrm{N}=30 ; 63.8$ per cent) are in complete agreement with the introduction of ethical standards within the accreditation process of hospitals $(\mathrm{M}=5.40$; $\sigma=1.08$ )

Concerning the introduction of ethical audit within the accreditation process, 53.2 per cent $(\mathrm{N}=30)$ expressed complete agreement, and 31.9 per cent $(\mathrm{N}=15)$ agreement $(\mathrm{M}=5.26$; $\sigma=1.09$ ).

A high percentage of $57.4(\mathrm{~N}=27)$ expressed complete agreement regarding the beneficial role of ethical monitoring in management of Romanian healthcare institutions $(\mathrm{M}=5.38 ; \sigma=0.97)$. The same percentage of respondents confirm that it would be beneficial to introduce ethical auditing for the accreditation process to increase performance of healthcare institutions $(\mathrm{M}=5.28 ; \sigma=1.08)$.

A percentage of 46.8 respondents $(\mathrm{N}=22)$ expressed complete agreement that they would be available to participate in the process of ethical auditing, while 31.9 per cent $(\mathrm{N}=15)$ expressed agreement $(\mathrm{M}=5.09 ; \sigma=1.21)$. There is strong dependence between the variable (availability to participate) and the introduction of ethical auditing within the accreditation process with a correlation coefficient of +0.70 (Ecart-type of the regression coefficient 0.095). The first variable explains 49 per cent of variation in the second variable. As far as concrete advantages are concerned, 68.1 per cent of respondents $(\mathrm{N}=32)$ showed complete agreement that public trust would be consolidated if hospitals provide superior quality medical services $(M=5.36 ; \sigma=1.11)$. A percentage of 34 per cent completely agreed, while 34 per cent agreed that integration of the ethical audit into accreditation criteria would improve the classification of hospitals ( $M=4.89$; $\sigma=1.09$ ). Inclusion of ethical audits might contribute to a more efficient allocation of resources (36.2 per cent accord or agreement and 34 per cent total accord or agreement; $\mathrm{M}=4.79 ; \sigma=1.32$ ). (Inclusion of the ethical audit in the accreditation process explains 61 per cent in the consolidation of public trust (correlation coefficient +0.78 , ecart-type of the regression coefficient -0.095 ).

There is also a strong, positive dependence between the variable regarding the beneficial role of the introduction of ethical monitoring in the management of Romanian healthcare institutions and the variable regarding the introduction of ethical auditing within the accreditation process. The correlation coefficient is +0.87 (ecart-type of the regression coefficient -0.083$)$, with the former variable explaining 75 per cent of the latter's variation.

A matter of concern is the perceived preparedness of managers for elaborate ethical policies. Responses were rather heterogeneous: 4 respondents ( 8.5 per cent) completely agreed that they are sufficiently trained, 11 (23.4 per cent) agreed, and 12 (25.5 per cent) were in partial agreement. A similar answer was given to the question regarding the extent to which Romanian hospitals are prepared for ethical 
auditing: the greatest number of those questioned $(\mathrm{N}=16.34$ per cent) only partially agreed with this statement, and only 4 completely agreed (8.5 per cent). For dependence between the variables (managers are prepared for elaborate ethical policies and (healthcare institutions are prepared for an ethical audit) there was a significant and positive relationship, the correlation coefficient being +0.79 (Ecart-type of regression coefficient $-0.088)$, the former explaining 62 per cent of the latter's variation.

Related to the above questions is the following one regarding the problem of whether managers receive sufficient support and resources for implementing elaborate ethical policies and standards at the institutions they lead. Fourteen respondents (29.8 per cent) expressed partial disagreement $(\mathrm{M}=3.43$; $\sigma=1.26)$. Thirteen (27.7 per cent) expressed partial agreement on whether managers are sufficiently competent for this task. Only 3 (6.4 per cent) expressed their complete agreement. Logically, a big number of respondents $(\mathrm{N}=30 ; 63.8$ per cent) consider that managers need supplementary preparation in order to be able to elaborate ethical policies and standards for the institutions that they lead $(\mathrm{M}=5.51 ; \sigma=0.75)$.

Over half of the respondents (59.6 per cent; $\mathrm{N}=28$ ) completely agreed that the managers of hospitals should be consulted with regard to the introduction of ethical audits among the criteria of the accreditation process $(\mathrm{M}=5.19$; $\sigma=1.31)$. A percentage of 46.8 per cent $(\mathrm{N}=$ 22) and 31.9 per cent $(\mathrm{N}=15)$ expressed complete agreement and agreement for taking part in an ethical audit.

\section{5}

\section{Discussion and research limitations}

The consultation of executives regarding the introduction of the ethical audit among the evaluative criteria of the accreditation process of hospitals certainly represents an important step for the assessment of their availability to involve themselves and the institutions they lead in such a process.

The research shows that over half of the managers are in complete agreement with the introduction of ethical standards within the accreditation process of hospitals. This shows that they consider the introduction of the ethical audit within the accreditation process as being relevant and pertinent and that ethical monitoring is beneficial for the activity of healthcare institutions. As can be seen from their responses, the most important gain is the consolidation of public trust regarding access to medical service of superior quality. These ethical audits also allow for proper classification of hospitals and for better allocation of resources according to ethical efforts by organisations. The results are all the more convincing, because participants involved (quality management at institutions) draw a clear line between abiding by ethical principles and quality assurance. The findings therefore support the introduction of ethical auditing within the accreditation process, which in turn improves the quality of medical services.

Among the problems identified by executives, is the insufficient preparation and training of managers for conducting ethical audits. The solution to this challenge is supplementary training for managers.

Findings of this research demonstrate that Romanian healthcare institutions are only partially prepared for ethical evaluation, and a strong concern for ethical values is not manifest.

The idea of defining ethical requirements for healthcare institutions through the accreditation is also expressed by Morrison (2011: 239). Ethical auditing would guarantee standard requirements. If only a few healthcare institutions which are really concerned with the championing of ethical values apply audits, their effect would not be capitalised and would only have a limited sphere of impact. Ethical audits are costly (which implies legal justification for the resources involved) and in order to reach an adequate degree of objectivity, they must be handled by external specialists. Many hospital managers do not appreciate the advantages of ethical audits especially given the pressure of lack of resources and the absence of managerial contractual obligations. In this context, the problem of integrating ethical auditing into the accreditation process of healthcare institutions arises. There are many beneficial effects through the "forced" implementation of this 
instrument. Adding criteria to the accreditation process requires consistency and realism.

The actual accreditation standards proposed by the National Commission of Hospital Accreditation $\left(\mathrm{CoNAS}^{2}\right)$ in Romania might add to the list of verification for the presence or absence of stricter managerial and performance aspects, but their foundation has a basis of respect towards ethical values. By taking into account ethical audits, it might be possible to offer concrete answers concerning the preoccupation with ethical values when utilising certain instruments. Questions that could be asked are the following:

- What are the ethical values that should be taken into account to support the mission of each hospital?

- What are the ethical values that could be developed to satisfy the patient and what are the results of these values?

- What are the mechanisms for the implementation of ethical policies (ethical programmes, ethical codes, training modules on ethical themes);

- What are the components of organisational structure (ethical committees and commissions, ethical lines, ethical counsellors) with responsibilities in ethical monitoring and which of these could be addressed by patients and employees when faced with ethical dilemmas and problems?

- How can work climate be characterised from an ethical point of view and what is its relationship with the employee's performance?

- What are the ethical aspects endorsed within public relations strategy?

- To what extent does the strategic plan take into account the activity's effects upon the environment?

- What are the ethical values which sustain the functionality of the communication system, etc.?

Healthcare authorities have a picture of what is going on at the macro-level of the healthcare system and have useful and necessary information for high-level decision-making processes. Integration of the entire healthcare system transforms the ethical audit into a control instrument, but also into an instrument of classification of healthcare units. Mandatory ethical audits within the accreditation system lead to a more efficient allocation of resources. Implicitly, institutions would be more motivated to increase their performance in order to be granted greater access to resources.

As Loewy (1999) argues, each system has unique ethical problems, and each country's healthcare system is marked by its own values and societal structures.

The main limitation of this research is that a small sample of subjects was used, which does not make it possible to generalise results.

The relatively small research sample, might designate this study as being a pilot. However, this is the first study of its kind in Romania and is an initial step to creating awareness for hospital managers (especially those involved in quality assurance) that their institutions may be subject to audits of ethics in the accreditation process. In spite of this limited character, the study might be useful for sounding an alarm bell or for suggesting a direction towards the qualitative and quantitative improvement of accreditation criteria and towards the management of change in Romanian healthcare institutions and worldwide. This change would consolidate fidelity towards each organisational mission, benefitting all categories of stakeholders.

\section{6}

\section{Conclusion and further research}

Research shows that managers are open to the idea of introducing the ethical audit as an institutional accreditation criterion. Managers used in this study could be the first group of sup-porters to recommend to the responsible authorities the introduction of ethical auditing in hospitals. At the same time, it is important to remember that preparation is needed in this area.

Ethical auditing is a proactive process, which aims at improving the ethical performance of healthcare institutions.

Through auditing, every healthcare institution might convey to its (internal and external) stakeholders a message about its ethical preoccupations with respecting moral values, about its constant efforts made in order to provide medical services at the highest level of quality, gaining in this way their trust and support. 
From an economic point of view, the results of an ethical audit might contribute to the classification of healthcare units in order to obtain a fair allocation of resources, which would create a competitive framework and ensure their progress and improvement.

Future research could aim at including a larger number of subjects. To have a complete picture, a future study should follow the integrated opinion of hospital managers, employees, the authorities that are responsible and interested in accreditation of hospitals, patients and lastly the community.

\section{Endnotes}

1 The Joint Commission on Accreditation of Healthcare Organizations (JCAHO/JACHO) (now Joint Commission) is "... a private non-governmental agency that establishes guidelines for the operation of hospitals and other health care facilities, conducts accreditation programs and surveys, and encourages the attainment of high standards of institutional medical care..." (http://medical-dictionary.thefreedictionary.com/Joint+Commission+on+Accreditation+of+Healthcare+ Organizations)

2 The National Commission of Hospital Accreditation (CoNAS) in Romania has among its main responsibilities: the approval of a hospital accreditation; the approval of procedures, standards and methodologies for accreditation of hospitals; the proposal of strategies to improve the quality of hospital services (http://www.conas.gov.ro/despre.html).

\section{Acknowledgement}

This paper is part of broad research developed within the framework of the European project entitled "Studii postdoctorale în domeniul eticii politicilor de sănătate" (POSDRU/89/1.5/S/61879).

\section{Authorship Statement}

All authors contributed equally to this paper.

\section{References}

CASSIDY, J. 1998. Calvary hospital focuses on ethics. Health Progress, 79(6):45.

CHELCEA, S. 2001. Metoda cercetării sociologice. Metode cantitative și calitative. București: Ed. Economică.

COLLIER, J., RORTY, M. \& SANDBORG, C. 2006. Rafting the ethical rapids. HEC Forum, 18(4):332-341. DOLAN, T. C. 2004. A time for ethical leadership. Healthcare Executive, 19(1):6-8.

FERRELL, O.C., FERRELL, L. \& FRAEDRICH, J. 2012. Business ethics, ethical decision making and cases. USA: South-Western Publishing.

GARÇIA-MARZA, D. 2005. Trust and dialogue: Theoretical approaches to ethics auditing. Journal of Business Ethics, 57:209-219.

HOFMANN, P.B. 1995. Healthcare management and ethics. Healthcare Executive, 10(1):46.

HOFMANN, P.B. 1995. Performing an ethics audit. Healthcare Executive, 10(Â6) (Nov./Dec.):47.

HOFMANN, P. B. 2011. 7 Factors complicate ethical resource allocation decisions, Healthcare Executive, 26.3:62-63.

HOFMANN, P.B. 2012. Fear of conflict: management and ethical costs, Healthcare Executive, 27(1):58

HOFMANN, P.B. 2006. The value of an ethics audit. Healthcare Executive Journal, 21(2).

HOFMANN, P.B. 1995. Performing an ethics audit. Healthcare Executive Journal, 10(6).

HOGSTEL, M.O. \& CURRY, L.C. 2004. Ethics committees in long-term care facilities, Geriatric Nursing, 25(6):364-369.

JOHNSTON, S.E., CRUESS, S.R. \& CRUESS, R.L. 2001. Ethical leadership in modern medicine. Canadian Journal of Administrative Sciences, 18(4):291.

JOINT COMMISSION ON ACCREDITATION OF HEALTHCARE ORGANIZATIONS 1998. Ethical issues and patient rights: across the continuum of care. Oakbrook Terrace, IL, USA.

KAPTEIN, M. 1998. Ethics management: auditing and developing the ethical content of organizations. Dordrecht, Netherlands: Kluwer.

KIRKPATRICK, W.J., REAMER, F.G. \& SYKULSKI, M. 2006. Social work ethics audits in health care settings: A case study. Health \& Social Work, 31(3):225.

LACHMAN, V.D. 2008. Patient safety: The ethical imperative, Dermatology Nursing, 20(2). 
LANDMAN, W.A., MOUTON, J. \& NEVHUTALU, K.H. 2001. Chris Hani Baragwanath Hospital Ethics' Audit. Ethics Institute of South Africa. Research Report no. 2. Available at: http://ethicssa.intoweb.co.za/UserFiles/ ethicssaintoweb.co.za/CHBHFinalReport.pdf [accessed 2012-05-01].

LOEWY, E.H. 1999. Health-care systems and ethics: What can we learn? Health Care Analysis, 7:309-320. MADDALENA, V. 2007. A practical approach to ethical decision-making, Leadership in Health Services, 20(2):71-75.

MORRISON, E. 2011. Ethics in health administration: a practical approach for decision makers. Sudbury, MS: Jones and Bartlett Publishers.

MENZEL, D.C. 2007. Ethics management for public administrators: Building organizations of integrity. Armonk, NY: M.E. Sharpe.

MORRELL, C. 2002. Ethical audit. Nursing Children and Young People, 14(7):3.

NEFT-SMITH, G., SCOTT, SPENCER, EDWARD M. \& FLETCHER, J.C. 1997. Ethics program evaluation: The Virginia Hospital Ethics Fellows Example, part II. H E C Forum, 9(4):375-388.

NELSON, W.A., WEEKS, W.B., CAMPFIELD, J.M. 2008. The organizational costs of ethical conflicts. Journal of Healthcare Management, 53:1.

PIENAAR, J. 2010. Ethics in economic and management sciences: a researcher's resource. SAJEMS, 13(2):177-189.

POITRAS, G., MEREDITH, L. 2009. Ethical transparency and economic medicalization. Journal of Business Ethics, 86:313-325.

PORTER, M. 1994. The audit explosion. London: Demos.

REAMER, F.G. 2007. Conducting an ethics audit. Social Work Today, 7(1). Available at: http://www.socialworktoday.com/archive/EoEJanFeb07.shtml [accessed 2012-05-14]. ROBERTS, M.J., REICH, M.R. 2002. Ethical analysis in public health. THE LANCET, 359.

SQUAZZO, J.D. 2012. Ethical challenges and responsibilities of leaders, Healthcare Executive, 27(1):32. SCHLEGELMILCH, B.B. 1998. Marketing ethics: an international perspective. London: International Thomson Business Press.

SLOSAR, J.P. 2004. Ethical decisions in health care. Health Progress, 85(1):38.

WEBER, L.J. 2001. Business ethics in healthcare: beyond compliance. Bloomington: Indiana University Press.

WEINSTEIN, H. C. 2002. Ethics issues in security hospitals, behavioral sciences and the law. Behav. Sci. Law, 20:443-461 WU, M.H., LIAO, C.H., CHIU, W.T., LIN, C.Y. \& YANG, C.M. 2011. Can we accredit hospital ethics? A tentative proposal. Journal of Medical Ethics, 37(8):493-497. 